\title{
Mortality among employees at a plastics and resins research and development facility
}

\author{
Sally R Cowles, Shan P Tsai, Elizabeth L Gilstrap, Charles E Ross
}

\begin{abstract}
Objectives-The study was undertaken to update a previous study of employees from a resins and plastics research and development facility and to further examine the mortality of these employees with particular emphasis on deaths due to pancreatic cancer.
\end{abstract}

Methods-This retrospective cohort study examined mortality from 1962 to 1992 for 257 men who were employed for at least one year during a 14 year period from 1962 to 1975 at a plastics and resins research and development facility. During the operative period, the primary activities involved applications and process development for polypropylene, polystyrene, epoxy resins, and to a lesser extent high density polyethylene.

Results-The cohort was young and was followed up for an average of 26 years. Although mortality for all causes among employees who worked at least one year at this facility was low (standardised mortality ratio (SMR) 0.74 ), the death rate from cancer was moderately higher than that of the general population (14 observed and 9.4 expected deaths). There were four observed and 0.5 expected deaths from pancreatic cancer among men who worked at this facility for at least one year, which resulted in a statistically increased SMR of 8.88 (95\% confidence interval $2 \cdot 42-22 \cdot 74)$. All cases of pancreatic cancer had "laboratory" jobs, and their ages at death were relatively young compared with deaths in the general population from pancreatic cancer. Lung cancer mortality was high but not significant with seven observed and 3.5 expected deaths. There were no deaths due to non-malignant respiratory disease ( 1.9 expected).

Conclusions-The increased cancer mortality was entirely due to excess deaths from pancreatic and lung cancers. No causative agent or process for these cases of pancreatic cancer has been identified. This study shows no increased colorectal cancer mortality as was found among another group of workers involved in the manufacture of polypropylene.

(Occup Environ Med 1994;51:799-803)

Keywords: pancreatic cancer; laboratory workers; cohort mortality study
The Woodbury (New Jersey) Plastics and Resins Technical Center (WPRTC) was in operation from 1962 to 1975 . During its 14 year existence, the primary activities at the WPRTC involved research and development work in the areas of customer technical service, applications and process development for polypropylene, polystyrene, epoxy resins, and to a far lesser extent high density polyethylene.

From 1962 to 1968 the WPRTC was involved with the applications and process development of thermoplastics with an emphasis primarily on polypropylene, secondly polystyrene, and lastly polyethylene polymer. New products were developed in the applications laboratory. An on site pilot plant was used to support process development. Pilot plant operations ran continuously for polystyrene between 1962 and 1968 and for polypropylene between 1962 and 1970. In 1965 some Shell research and development operations that had been based in California moved to the WPRTC and increased the emphasis on polypropylene copolymers and catalysts. Most polystyrene pilot plant work stopped in 1968 when a Shell manufacturing plant in Belpre, Ohio opened. Product development and applications work on epoxy resins were added in 1969 with the move of Shell epoxy resins research and development personnel from another laboratory in New Jersey. Both pilot plant and applications laboratory space were used for thermoplastics and thermoset work after 1969. During the period 1970-1975 the pilot plant housed only polypropylene copolymer development work, catalyst work, and resins work.

The mortality of employees who ever worked at the WPRTC was first examined in 1986 in response to concerns about one suspect and two definite deaths due to pancreatic cancer among former employees at the WPRTC. The results of a retrospective cohort study that evaluated employees who worked at this facility from 1962 to 1975 and were followed up for mortality to 1985, suggested a possible excess of pancreatic cancer (standardised mortality ratio $(\mathrm{SMR})=7 \cdot 35,95 \%$ confidence interval (95\% CI) 0.83-26.54). ${ }^{1}$ As the excess of pancreatic cancer was based on only two definite cases, the original investigators recommended further follow up of this group of employees. The primary objective of our study was to update the previous study with an additional seven years of follow up and to examine further the mortality of employees at the WPRTC, with particular 
emphasis on deaths due to pancreatic cancer.

\section{Materials and methods}

The study population consists of all WPRTC employees $(n=414)$ who worked at least one day from 1 January 1962 to 31 December 1975. This study reports the SMR results of all male employees who worked for at least one year at WPRTC as well as at least one day at WPRTC; female workers $(n=71)$ were omitted from the mortality analysis due to small numbers and the fact that they worked primarily in unexposed jobs. Cohort members were identified based on the information collected by Shell Corporate Medical Department for the original investigators. Data sources included a list of employees at the WPRTC and their employment dates based on laboratory logs and employee service records. For the purposes of statistical analysis, all cohort members were treated as white, as all but four employees at the WPRTC were white or of unknown race.

Several sources were used to update the vital status of the cohort members to 31 December 1992. These included company records, the National Death Index, and the Social Security Administration's Master Beneficiary Record file. There were no employees lost to follow up; employees who had left work and were not identified by the National Death Index search or the Social Security Administration search were assumed to be alive $(n=299)$. Death certificates were obtained either from company benefits files or from respective state vital statistics departments. The underlying cause of death was coded independently by two trained nosologists according to rules of the International Classification of Diseases (ICD) in effect at the time of death and then converted to the eighth revision of the ICD (ICD-8), which was used in the analysis.

Employees entered the study on 1 January 1962 if they began employment at WPRTC on that date. Otherwise he or she entered the study on the date of employment at this facility. Person-years were accumulated from the entry date to the date of death or the end of the study, whichever came first.

Table 1 Observed and expected deaths and SMRs for selected causes of death among men who worked for at least one year at the WPRTC

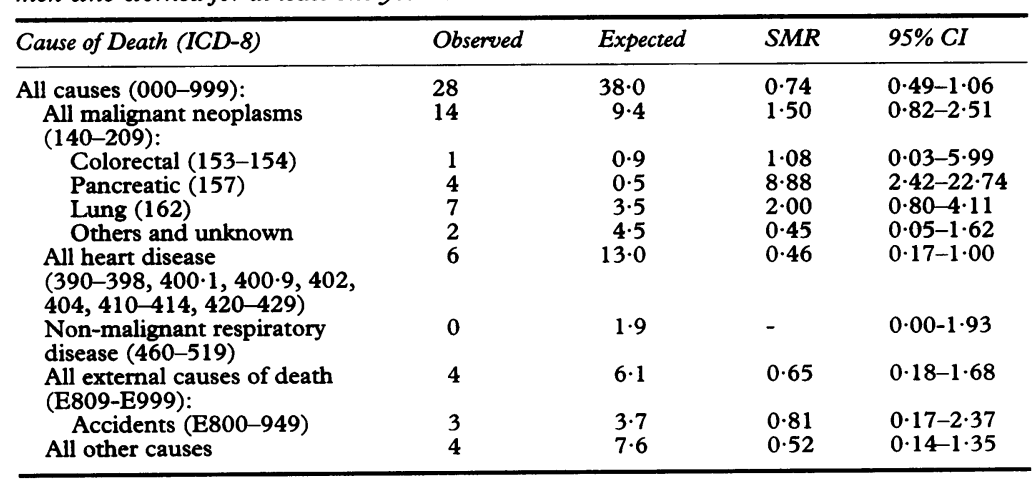

Excesses and deficits of mortality in this study are expressed as SMRs that were calculated with the Occupational Cohort Mortality Analysis Program. ${ }^{2}$ The SMR is the number of observed deaths in the study cohort divided by the number of deaths that would be expected if death rates for a comparison population were in effect. The expected number of deaths were calculated based on the age, sex, cause, and calendar time specific death rates for white men and white women of the United States. To adjust for geographic variations in mortality and the potential influence of confounding factors, the expected number of deaths was also computed from death rates for New Jersey. The $95 \%$ CI for each SMR was calculated and the SMR's deviation from 1.00 was tested assuming a Poisson distribution for the observed deaths with a two sided test of significance. ${ }^{3}$

\section{Results}

A total of 343 men were included in this study. The average age at entry into the cohort was 29. The total number of personyears of observation was 8752 , and subjects were followed up for an average of 25.5 years. The average total duration of employment at WPRTC was 3.3 years. Twenty-six percent of the men were hired by Shell before 1962 and transferred to WPRTC during its 14 years in operation. The SMR results for the 257 men who worked for at least one year at WPRTC follow.

Based on United States comparisons, table 1 shows the observed and expected number of deaths, SMRs, and their $95 \%$ CIs for selected causes of death for the 257 men. A total of 28 deaths were observed whereas 38 were expected, with a resultant SMR for all causes of $0.74(95 \%$ CI $0.49-1 \cdot 06)$. There were 14 observed compared with $9 \cdot 4$ expected cancer deaths, a non-significant difference (SMR $1.50 ; 95 \%$ CI $0.82-2.51$ ). The mortality for cancer of the lung was moderately increased with an SMR of $2 \cdot 00$ (95\% CI 0.80-4.11). The observed numbers of deaths from heart disease (SMR 0.46; 95\% CI 0.17-1.00) and all external causes (SMR 0.65; 95\% CI $0 \cdot 18-1.68$ ) were substantially lower than expected. There were four deaths from pancreatic cancer, compared with 0.5 expected, which resulted in a significant SMR of 8.88 (95\% CI 2-42-22·74). Pancreatic cancer mortality was also analysed by 10 years time since first exposure; the SMR was 10.24 (95\% CI $2 \cdot 79-26 \cdot 23)$. There was one colorectal cancer with 0.9 expected. The number of deaths for all cancers other than pancreatic was about the same as expected (10 observed and nine expected; SMR 1.12; 95\% CI 0.54-2.07).

We investigated the work histories for the decedents from pancreatic cancer and lung cancer. One additional death due to adenocarcinoma of the abdomen, primary unknown, was also included in this evaluation because medical records indicated that the treating physician's working diagnosis was cancer of the pancreas. This man had worked 
Table 2 Deaths from cancer of the pancreas in employees of WPRTC

\begin{tabular}{|c|c|c|c|c|c|c|c|}
\hline $\begin{array}{l}\text { Case } \\
\text { No }\end{array}$ & $\begin{array}{l}\text { Year of } \\
\text { death }\end{array}$ & $\begin{array}{l}\text { Age of } \\
\text { death }\end{array}$ & fob title & Areas worked at WPRTC & $\begin{array}{l}\text { Years } \\
\text { worked }\end{array}$ & $\begin{array}{l}\text { Areas worked at } \\
\text { other Shell locations }\end{array}$ & $\begin{array}{l}\text { Years } \\
\text { worked }\end{array}$ \\
\hline 1 & 1979 & 53 & Engineer & $\begin{array}{l}\text { Plastics technical service, } \\
\text { applications lab }\end{array}$ & $1962-66$ & $\begin{array}{l}\text { Norco refinery - mechanical engineer } \\
\text { Emeryville labs-service engineer } \\
\text { Union labs-plastics technical services } \\
\text { Chicago-marketing development, plastics } \\
\text { New York-marketing development, plastics } \\
\text { Houston-product manager, development }\end{array}$ & $\begin{array}{l}53-55 \\
55-61 \\
61-62 \\
66-68 \\
68-70 \\
70-79\end{array}$ \\
\hline 2 & 1985 & 43 & Chemist & $\begin{array}{l}\text { Polymer chemistry, analytical and } \\
\text { process, plastics products, } \\
\text { applications lab, pilot plant } \\
\text { labs }\end{array}$ & $\begin{array}{l}1968 \\
1970-75\end{array}$ & $\begin{array}{l}\text { Military leave } \\
\text { Woodbury plant-catalyst products } \\
\text { Westhollow research centre-plastics } \\
\text { Houston-technical support, polymers } \\
\text { Norco-technical manager, polypropylene } \\
\text { Houston-manager, plastics }\end{array}$ & $\begin{array}{l}68-70 \\
74 \\
75-77 \\
77-79 \\
79-82 \\
82-85\end{array}$ \\
\hline 3 & 1992 & 62 & $\begin{array}{l}\text { Lab } \\
\text { technician }\end{array}$ & $\begin{array}{l}\text { Plastics technical service, } \\
\text { applications lab, resins }\end{array}$ & $1969-75$ & $\begin{array}{l}\text { Union labs - marketing production and development } \\
\text { Woodbury plant - technical/product } \\
\text { testing }\end{array}$ & $\begin{array}{l}53-69 \\
75-87\end{array}$ \\
\hline 4 & 1992 & 52 & Chemist & $\begin{array}{l}\text { Polypropylene catalysts, styrene } \\
\text { plastics, appalications lab, pilot } \\
\text { plant labs, polymer chemistry }\end{array}$ & $1966-69$ & $\begin{array}{l}\text { New York - marketing development, plastics } \\
\text { Houston-polystyrene department, } \\
\text { purchasing }\end{array}$ & $\begin{array}{l}69-70 \\
70-74\end{array}$ \\
\hline $5^{\star}$ & 1984 & 42 & Engineer & $\begin{array}{l}\text { Technical service, applications lab } \\
\text { Production development, injection molding, } \\
\text { impact copolymers }\end{array}$ & $\begin{array}{l}1965-68 \\
1972-75\end{array}$ & $\begin{array}{l}\text { Woodbury - marketing } \\
\text { New York - marketing development, plastics } \\
\text { Houston-plastics business team } \\
\text { Westhollow Research Centre-polypropylene } \\
\text { process and product }\end{array}$ & $\begin{array}{l}64 \\
68-70 \\
70-72 \\
75-84\end{array}$ \\
\hline
\end{tabular}

${ }^{\star}$ Death certificate cause $=$ adenocarcinoma metastatic, primary unknown; attending physician's diagnosis $=$ cancer of pancreas.

at WPRTC with one of the confirmed cases from 1972-1975.

Table 2 provides information on duration of employment at the WPRTC, major areas worked at WPRTC and other Shell locations, job title, year of death, and age at death for the four definite and one suspected cases of pancreatic cancer. Of particular note are the relatively young ages at death for the cases (average age of death 50) and the finding that all cases had "laboratory" jobs at the WPRTC. All cases had some work in the applications laboratory, and cases $1,2,4$, and 5 were involved in polypropylene product development. Cases 1, 2, and 5 were specifically engaged in a polypropylene stretch tape extrusion development project related to production of sandbags for use in the Vietnam war. Chemical exposures are likely to have included a wide variety of catalyst components and additives designed to produce better polypropylene products. Table 3 presents some chemical categories used at WPRTC. Case 3 was primarily an epoxy resins expert who may have provided advice and consultation to thermoplastic polymer development personnel working in the applications laboratory. All cases spent a longer tenure at Shell locations other than WPRTC; work areas include laboratories, manufacturing facilities, and head office.

Six of the seven deaths from lung cancer had previously worked at the Union, New Jersey laboratory that focused on epoxy resins and solvents, before being transferred to WPRTC. Twenty four years was the average duration of employment with Shell, but only $5 \cdot 3$ years were spent at WPRTC. An examination of their work histories showed three chemists, three laboratory technicians, and one manager. Four of the cases spent most of their WPRTC service in the epoxy resins group, two in thermoplastics, and one in an analytical and process group. The average age at death was 61 (range $=45-71$ ). Interviews with coworkers showed that six of the seven cases were heavy smokers, with the smoking status of the seventh case being unknown.

The observed and expected number of deaths, SMRs, and their $95 \%$ CIs for selected causes of death for the 343 men who worked at least one day at WPRTC was also examined. The SMR for pancreatic cancer in this group was 7.00 (95\% CI 1.91-17.91). Similarly, lung cancer mortality was also increased, although the excess was not significant (SMR 1.64; 95\% CI 0.66-3.38). The raised SMR for all cancers combined (SMR $1 \cdot 25 ; 95 \% \mathrm{CI}$ $0 \cdot 70-2 \cdot 06$ ) was entirely due to the increased deaths from these two cancer sites, and the deaths from lung cancer are likely to be attributable to cigarette smoking.

With mortality rates for the New Jersey white male population, analyses were also performed for male employees who worked for at least one year at the WPRTC. The cause

Table 3 Chemicals at WPRTC

\begin{tabular}{|c|c|}
\hline Category & Examples \\
\hline Catalysts & $\begin{array}{l}\text { Aluminium alkyls, titanium } \\
\text { tetrachloride, titanium trichloride, } \\
\text { titanium dichloride, sesqui chlorides }\end{array}$ \\
\hline Stabilisers & $\begin{array}{l}\text { Phenolics, amines, sulphur esters, } \\
\text { ionol, antistatic compounds }\end{array}$ \\
\hline $\begin{array}{l}\text { Nickel dibutyl thio } \\
\text { carbamate }\end{array}$ & 一 \\
\hline Elastomers & $\begin{array}{l}\text { Ethylene propylene rubber, ethylene } \\
\text { propylene diene monomer, kratons }\end{array}$ \\
\hline Mineral fillers & Asbestos, talc, glass \\
\hline Comonomers & $\begin{array}{l}\text { Acrylonitrile, butene, propylene, } \\
\text { ethylene }\end{array}$ \\
\hline Acrylates & Ethyl acrylate \\
\hline Laboratory solvents & $\begin{array}{l}\text { Carbon tetrachloride, toluene, } \\
\text { trichlorobenzene, benzene, } \\
\text { methylene chloride, pyridine }\end{array}$ \\
\hline Pigments & $\begin{array}{l}\text { Titanium dioxide, carbon black, } \\
\text { copper-phthallo compounds, iron, } \\
\text { lead, cadmium }\end{array}$ \\
\hline Styrene monomer & Vent fumes \\
\hline $\begin{array}{l}\text { Fire retardants } \\
\text { Dowtherm }\end{array}$ & $\begin{array}{l}\text { Antimony, bromo compounds } \\
\text { Heating oil }\end{array}$ \\
\hline Resins & $\begin{array}{l}\text { Bisphenol acetone, } \\
\text { epicholorohydrin, epon-1002, } \\
\text { phenol, aromatic amines, glycidyl } \\
\text { ethers, liquid resins, aliphatic } \\
\text { amines, anhydrides, Lewis acids }\end{array}$ \\
\hline Plastics & $\begin{array}{l}\text { Polypropylene, polystyrene, } \\
\text { polyethylene }\end{array}$ \\
\hline $\begin{array}{l}\text { Polypropylene oligomers } \\
\text { Mineral oil }\end{array}$ & 二 \\
\hline
\end{tabular}


specific mortality pattern for cancer is virtually the same as that with the United States population for comparison. For example, the SMR was 8.53 (95\% CI 2.32-21.83) for pancreatic cancer, $2 \cdot 11(95 \%$ CI $0.85-4.34)$ for lung cancer, and 0.91 (95\% CI 0.02-5.06) for colorectal cancer.

\section{Discussion}

This study examined mortality from 1962 to 1992 for a cohort of 343 men who were employed for at least one year as well as those employed for at least one day during a 14 year period from 1962 to 1975 at a plastics and resins research and development facility. The WPRTC employees comprise a small and relatively young group, with $78 \%$ of the total 8752 male person-years of follow up occurring in people under the age of 50 . Therefore, the numbers of observed and expected deaths are small and the SMRs are relatively unstable as reflected by wide CIs. The large deficits of overall mortality and heart disease among men in this study are probably due to a combination of the healthy worker effect, ${ }^{4-7}$ the relatively high socioeconomic status (most were chemists, engineers, or technicians), and the benefits of employment. The overall cancer mortality among men at the WPRTC was moderately higher than that of the general population. This increase in mortality from overall cancer was entirely due to the excess deaths from pancreatic and lung cancers.

The magnitude of SMRs for pancreatic cancer was similar to that of the original study (1962-1985) although the original study SMR was found not to be significant (SMR 8.72; 95\% CI 0.98-31.47). Two new cases were added in this update; the SMR for the 1986-1992 update period is $9 \cdot 1$ (95\% CI $1 \cdot 10-32 \cdot 8)$. Pancreatic cancer is a disease that accounts for about $5 \%$ of the total cancer deaths in the United States each year. ${ }^{8}$ Pancreatic cancer mortality and incidence have been fairly stable in the last 20 years. $^{8}$ The causes of this disease are not well known. An established risk factor for pancreatic cancer is cigarette smoking; the incidence is more than twice as high for smokers as non-smokers. ${ }^{8-12}$ A recent study showed a 14 to 16 - fold increase in the risk of pancreatic cancer among patients with chronic pancreatitis. ${ }^{13}$ Although alcohol and coffee intake and a high fat diet have been suggested as risk factors, these findings have not been conclusive. ${ }^{10-12}$ Socioeconomic, occupational, genetic, and migration effects are weak and inconsistent. ${ }^{9}$

Despite extensive study, no occupational cause has been shown or identified, but the continuing excess of pancreatic cancer in former WPRTC employees raises questions about a possible occupational relation for several reasons. The apparent clustering of cases in laboratory areas of WPRTC, in general, and the applications laboratory, in particular, raises the issue of a possible common exposure. Three of the four confirmed cases and the one suspect case all worked in polypropylene products areas, and one case worked on epoxy resins in the same applications laboratory; about half of the employees who worked for at least one year at WPRTC worked in the applications laboratory for some of their employment.

Also, the finding of additional deaths from cancer of the pancreas in this cohort after the initial case evaluations in 1986/87 indicates that this may be more than just a chance cluster. Also, the age at death (51) due to this cause is relatively young when the average age of death for a comparable age distribution in the general population is $59 .{ }^{14}$

In spite of these facts no causal exposure has been identified. The laboratory work involved potential exposure to a myriad of substances, and neither polypropylene nor epoxy resins have been identified as having any causal relation to pancreatic cancer. No individual exposure assessments or industrial hygiene measurements were available, and the work histories only provide department and area worked and no specific chemical information. Due to the nature of a research facility, projects and work processes changed rapidly over time and varied with each person. Interviews with former employees at the WPRTC and an extensive review of technical reports, monthly summaries, and lab logs identified WPRTC chemicals (table 3 ) but no definitive person specific information.

Other factors should be noted. Smoking is a recognised risk factor for pancreatic cancer; ${ }^{8-12}$ the smoking attributable mortality for pancreatic cancer among men in the United States is about $23 \% .{ }^{15}$ Two cases were definitely heavy smokers, one was a smoker but not a heavy one (the one suspect case), one was an ex-smoker, and one was not known as a smoker, but those coworkers interviewed could not be sure he was definitely a nonsmoker. There was no information on smoking for the overall cohort, but white collar workers generally smoke less than blue collar workers. ${ }^{16}$ Although the smoking rate for this cohort may be similar to or less than the general population at the time, there possibly might be potential synergistic effects of cigarette smoking and chemicals in the laboratory. The average duration of employment at WPRTC for the cohort was about three years of an average 12 years of employment with Shell. The cases' average duration of employment at WPRTC was 4.9 years and with Shell was 21 years, showing a longer Shell employment experience.

No similar excess mortality from pancreatic cancer in a working population exposed to polypropylene has been reported in the scientific literature by other companies among polymer research and development employees. There are several substances that have been suggestively linked to pancreatic cancer. For example, a recent cohort study found an increased pancreatic cancer mortality among employees in a plastics manufacturing and research and development facility. ${ }^{17} \mathrm{~A}$ subsequent case-control study of this population concluded that the excess of pancreatic cancer was more likely to be related to polyvinyl 
chloride processing. ${ }^{18}$ Other occupational studies have linked increased pancreatic cancer with exposure to DDT, ${ }^{19}$ and ethylene chlorohydrin production. ${ }^{20}$ Epidemiological studies also found excess risks of pancreatic cancer for people employed as chemists, ${ }^{21} 22$ dry cleaners, ${ }^{23}$ workers in electrical equipment manufacture, ${ }^{24}$ and in the rubber industry. ${ }^{25}$

Low lung cancer mortality among petroleum and chemical employees has been repeatedly reported, ${ }^{26} 27$ and lung cancer was not increased in other studies of employees in polymer research and development. ${ }^{17}$ Smoking is a major cause of lung cancer ${ }^{15}$; the smoking attributable mortality for lung cancer among men in the United States is about $90 \%$. The fact that six of the seven lung cancer cases $(86 \%)$ were known heavy smokers is the most likely reason for the increase in lung cancer among employees at the WPRTC.

An increased risk of colorectal cancer among workers involved with the manufacture of polypropylene has been reported, ${ }^{28}$ but the risk was not increased among employees at a polypropylene pilot plant. ${ }^{29}$ The mortality of colorectal cancer among employees at the WPRTC was not increased; there was only one observed death when 1.2 were expected. Due to small numbers, no definitive conclusions can be drawn about increased or decreased colorectal cancer mortality in this population. The WPRTC was adjacent to a polypropylene manufacturing plant that Shell sold in 1987. Shell employees (about 400) who worked at the plant did not experience any excess of pancreatic cancer, lung cancer, or colorectal cancer; there was only one death from lung cancer and none from colorectal cancer. The one death from pancreatic cancer occurred in an employee who had also worked at WPRTC, and thus was previously identified.

This study provided a unique opportunity to examine the mortality experience of a population of employees from plastics and resins research and development. Overall, the mortality of the employees at the WPRTC was similar to that of the general population. The increase of lung cancer is not likely to be related to employment at the WPRTC. Excess mortality was seen for pancreatic cancer in men. The cause of this increase remains unknown. An in depth review of work histories, location project logs, and monthly activity summaries was performed, but no specific chemical agent or exposure has been identified. The association with work in the applications laboratory was the only common factor found. Hundreds of different additives and catalysts were used at the WPRTC, and many experiments that did not reach the pilot plant were performed in the applications laboratory. We shall continue to track this cohort.
We thank Dr Philip Cole for his guidance and useful comments. We also gratefully acknowledge the following people for their assistance with this study: Don Wood, John Goodenbour, Dale Walker, Norm Peck, Don Brath, Art Otermat, Glen Short, Chris Uzelmeier, Robert Young Eleanor Gill, Robert Gould, and Terri Colangelo.

1 Delzell E, Cole P. An evaluation of mortality among employ ees of the Woodbury Technical Center. Philip Cole Associates, 1988.

2 Marsh GM, Preininger M. OCMAP: a user-oriented occupational cohort mortality analysis program. American Statistician 1980;34:245-6.

3 Bailar JC, Ederer F. Significance factors for the ratio of a Poisson variable to its expectation. Biometrics 1964;20: 639-43.

4 Fox AJ, Collier PF. Low mortality rates in industrial cohort studies due to selection for work and survival in the industry. American Statistician 1976;30:225-30.

5 Ott MG, Holder BB, Langner RR. Determinants of mortality in an industrial population. $\mathcal{F}$ Occup Med 1976; 18:171-7

6 Wen CP, Tsai SP, Gibson RL. Anatomy of the healthy worker effect: a critical review. $f$ Occup Med 1983;25: 283-9.

7 Monson RR. Observations on the healthy worker effect. f Occup Med 1986;28:425-33.

8 American Cancer Society. Cancer facts and figures-1993. Atlanta: American Cancer Society, 1993

9 Mack TM. Pancreas. In: Schottenfeld D, Fraumeni JF, eds. Cancer epidemiology and prevention. Philadelphia: WB Saunders, 1982:638-67.

10 Mack TM, Yu MC, Hanisch R, et al. Pancreas cancer and smoking, beverage consumption, and past medical history. $\mathcal{F}$ Natl Cancer Inst 1986;76:49-60.

11 Falk RT, Pickle LW, Fontham ET, et al. Life-style risk factors for pancreatic cancer in Louisiana: a case-control study. Am ₹ Epidemiol 1988;128:324-36.

12 Olsen GW, Mandel JS, Gibson RW, et al. A case-contro study of pancreatic cancer and cigarettes, alcohol, coffee, study of pancreatic cancer and cigarettes, alcoh

13 Lowenfels AB, Maisonneuve P, Cavallini G, et al. Pancreatitis and the risk of pancreatic cancer. $N$ Engl $f$ Med 1993;328:1433-7.

14 National Center for Health Statistics. Vital statistics of the United States, 1988. Vol II, mortality, part A. Washington: Public Health Service, 1991.

15 Center for Disease Control. Cigarette smoking-attributable mortality and years of life lost-United States, 1990. MMWR Morb Mortal Wkly Rep 1993;42:645-9.

16 Tsai SP, Dowd CM, Cowles SR, Ross CE. Prospective morbidity surveillance of Shell refinery and petrochemical employees. Br f Ind Med 1991;48:155-63.

17 Dell LD, Teta MJ. Mortality among workers at a plastics manufacturing and research and development facility: manufacturing and research and develop

18 Selenskas SL, Teta MJ, Vitale JN. Pancreatic cancer among workers processing synthetic resins. $A m$ f Ind Med (submitted)

19 Garabrant DH, Held J, Langholz B, et al. DDT and related compounds and risk of pancreatic cancer. $\mathcal{f}$ Nat Cancer Inst 1992;84:764-71.

20 Brenson LO, Teta MJ. Mortality due to pancreatic and ymphopoietic cancers in chlorohydrin production workers. Br f Ind Med 1993;50:710-16.

21 Li FP, Fraumeni JF, Mantel N, et al. Cancer mortality among chemists. F Natl Cancer Inst 1969;43:1159-64.

22 Hoar SK, Pell SA. A retrospective cohort study of mortality and cancer incidence among chemists. $\mathcal{F}$ Occup Med and cancer inciden

23 Lin RS, Kessler II. A multifactorial model for pancreatic cancer in man: epidemiologic evidence. $\mathscr{f} A M A 1981$; 245:147-52.

24 Mack TM, Paganini-Hill A. Epidemiology of pancreas cancer in Los Angeles. Cancer 1981;47:1474-83.

25 Delzell E, Louik C, Lewis J, et al. Mortality and cancer morbidity among workers in the rubber industry. $A m$ Ind Med 1981;2:209-16.

26 Wong O, Raabe GK. Critical review of cancer epidemiology in petroleum industry employees, with a quantitative meta-analysis by cancer sites. Am $\mathcal{F}$ Ind Med 1989; 15:283-310.

27 Teta MJ, Schnatter AR, Ott MG, Pell S. Mortality surveillance in a large chemical company: the Union Carbide lance in a large chemical company: the Union Carbide Corporation experi

28 Acquavella JF, Douglas TS, Phillips SC. An evaluation of excess colorectal cancer incidence among worker involved in the manufacture of polypropylene. $\mathcal{F}$ Occup Med 1988;30:438-42.

29 Acquavella JF, Owen CV. Assessment of colorectal cancer incidence among polypropylene pilot plant employees. f Occup Med 1990;32:127-30. 